\title{
Polymerization of Methyl Methacrylate with Radical Initiator Immobilized on the Inside Wall of Mesoporous Silica
}

\author{
By Kenji IKEDA, Mariko KIDA, and Kiyoshi ENDO*
}

Polymerization of methyl methacrylate (MMA) with a radical initiator covalently immobilized 4,4'-azobis(4-cyanopetanoyl) (ACP) group on the inside wall of MCM-41 (ACP-MCM-41) was investigated. The polymerization of MMA with ACPMCM-41 proceeded to give high-molecular weight polymers. The relationship between the $M_{\mathrm{n}}$ of the resulting polymer and the polymer yield gave a straight line, and the line passed through the origin, which is in contrast to that such relationship was not observed in the polymerization of MMA with dimethyl 2,2'-azobis(2-methyl propionate) (MAIB) even in the cavity of MCM-41. The results demonstrates that the termination reactions of the propagating radicals were extremely suppressed by movement restriction of the polymer chains covalently immobilized on the inside wall of MCM-41 in the polymerization of MMA. The presence of super long-lived propagating radical on the inside wall of MCM-41 was confirmed by ESR measurement and post-polymerization.

KEY WORDS: Immobilized Radical Initiator / MCM-41 / Mesoporous Silica / Long Lived Propagating Radical / Termination Reaction / Poly(methyl methacrylate) / ESR Measurement /

Mesoporous silica has been of great interest in the past decade for a large internal surface area, a well-defined pore size, and a capability of including relatively large molecules such as oligomers and polymers in the cavity. Properly functionalized and structurally ordered nanoporous materials such as MCM-type silica with a tunable pore size and a narrow pore-size distribution have attracted much attention for their potential applications as new catalysts for synthesizing desired products. ${ }^{1-8}$ Among many type of mesoporous silicas synthesized, MCM-41 belonged to a family of mesoporous silicates disclosed by Mobil researchers in $1992 .^{2}$

In the application of mesoporous silicas, they give a characteristic polymerization spaces for transition metals catalyzed olefin polymerizations. Polymerization of ethylene with half-titanocene/MAO catalyst in the cavity of MCM-41 was reported to give a high performance polymer with a fiber structure. 9 Polymerization of propylene with $\mathrm{Et}(\mathrm{ind})_{2} \mathrm{ZrCl}_{2} /$ MAO catalyst in the cavity of mesoporous silica afforded a high molecular weight polymer. ${ }^{10,11}$ Moreover, rac-ethylenebis(1-indenyl) $\mathrm{ZrCl}_{2}$ in combination with covalently anchoring $\mathrm{MAO}^{12}$ and borate ${ }^{13}$ on the inside wall of MCM-41 and polymerizations of olefins with organometallic compounds such as $\mathrm{Cr},{ }^{14} \mathrm{Mo},{ }^{15} \mathrm{Rh},{ }^{16}$ and $\mathrm{Ni}^{17,18}$ catalysts on the inside wall of MCM-41 were reported.

Polymerizations in the cavity of mesoporous silicas are influenced by the wall of host materials. Moller and his coworkers reported that a large amount of poly(MMA) was adsorbed in the pore volume of host material in the cavity of mesoporous silica in the radical polymerization of MMA. ${ }^{19}$ The weight of encapsulated poly(MMA) in the cavity of MCM41 increased with decreasing pore diameter. ${ }^{20}$ Radical polymerization induced with the initiator immobilized covalently on the inside wall of the mesoporous silicate cavity has been investigated to synthesize polymer-silica hybrid materials with well-defined mesoporosity. ${ }^{21}$ The encapsulations of organic polymers in the cavity of the mesoporous silica have been also studied. ${ }^{22,23}$

Although controlled polymerizations of vinyl monomers with a radical initiator bonded to the surface of silica particle have been achieved by many workers, ${ }^{24-33}$ a radical polymerization confined reaction space like a mesoporous silica is also an useful approach for the controlled reactions. Because a termination of growing radicals may be suppressed significantly by the restriction of the growing chain movement. Aida and his coworkers reported that a long lived polymer-radicals was confirmed by the polymerization of MMA in the MCM-41 cavity in the presence of $2,2^{\prime}$-azobisisobutyronitrile or benzoyl peroxide. $^{34}$

However, polymerizations of vinyl monomers with radical initiators covalently immobilized on the inside wall of MCM41 were not found in the literatures to our knowledge. If such initiators are used for the polymerization of vinyl monomers, a long lived propagating radical will be expected to be produced This leads to the molecular weight control of the polymer. To elucidate these points, we synthesized the radical initiator including 4,4'-azobis(4-cyanopetanoyl) group (ACP), which is covalently immobilized on the inside wall of MCM-41(ACPMCM-41), and polymerization of MMA was investigated.

\section{EXPERIMENTAL}

\section{Materials \\ MMA and dimethyl 2,2'-azobis(2-methyl propionate) (MAIB) (Wako Pure Chemical) were purified by distillation}

Department of Applied Chemistry and Bioengineering, Graduate School of Engineering, Osaka City University, Sugimoto, Sumiyoshi-ku, Osaka 5588585, Japan

*To whom correspondence should be addressed (Tel: +81-6-6605-2697, Fax: +81-6-6605-2697, E-mail: endo@a-chem.eng.osaka-cu.ac.jp). 

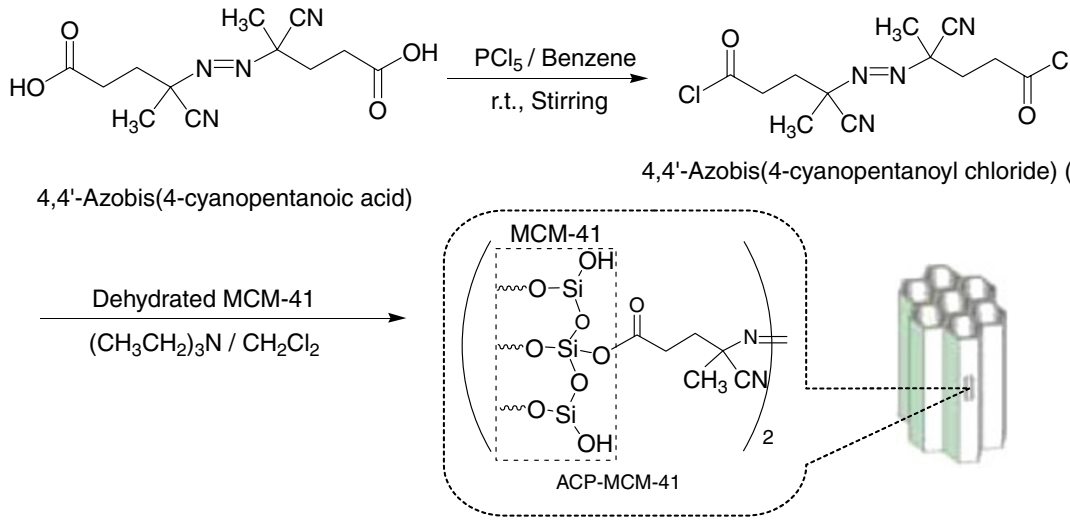

Figure 1. Synthetic method for ACP-MCM-41.

over calcium hydride before use. ACP-MCM-41 was synthesized as mentioned below, and used as a radical initiator. Other reagents were used after purification by conventional methods.

\section{Synthesis of MCM-41}

MCM-41 was synthesized by a similar method reported in the literature. ${ }^{35}$ Sodium silicate $(24.7 \mathrm{~g})$ was added to 133.3 $\mathrm{mL}$ of $\mathrm{H}_{2} \mathrm{O}$ and stirred for $15 \mathrm{~min}$. A solution of $10.6 \mathrm{~g}$ of hexadecyltrimethylammonium bromide in $66.7 \mathrm{~mL}$ of $\mathrm{H}_{2} \mathrm{O}$ was prepared by warming the mixture up to $45^{\circ} \mathrm{C}$ to dissolve the template. Then, the surfactant solution was added to the silicate slurry and stirred for $30 \mathrm{~min}$. The $\mathrm{pH}$ of the mixture was adjusted to 11 during an addition of $2.8 \mathrm{~g}$ of $\mathrm{H}_{2} \mathrm{SO}_{4}$ (95\%) in $20 \mathrm{~mL}$ of $\mathrm{H}_{2} \mathrm{O}$. The mixture was transferred into a static autoclave and heated to $100^{\circ} \mathrm{C}$. After $24 \mathrm{~h}$, the reaction vessel was allowed to cool down to $65^{\circ} \mathrm{C}$ and the $\mathrm{pH}$ was adjusted to 10 by an addition of $0.69 \mathrm{~g}$ of $\mathrm{H}_{2} \mathrm{SO}_{4}(95 \%)$ in $13.3 \mathrm{~mL}$ of $\mathrm{H}_{2} \mathrm{O}$. The reaction vessel was again sealed and the mixture was heated at $100^{\circ} \mathrm{C}$ for $24 \mathrm{~h}$. The white solid products were recovered by a filtration, washed with arge amounts of a distilled water, and dried at $25^{\circ} \mathrm{C}$ for $24 \mathrm{~h}$ under reduced pressure. The product was calcined at $540{ }^{\circ} \mathrm{C}$ for $6 \mathrm{~h}$ in air to remove the surfactant of the framework, and identified to be MCM-41 by the methods described in the literature. ${ }^{35,36}$

\section{Synthesis of ACPC}

4,4'-Azobis(4-cyanopetanoyl chloride) (ACPC) was synthesized by a similar method described in the literature. ${ }^{37} 4,4^{\prime}$ Azobis(4-cyanopentanoic acid) $(1.5 \mathrm{~g}, 5.4 \mathrm{mmol})$ in $15 \mathrm{~mL}$ of benzene was chilled in ice bath and treated with $\mathrm{PCl}_{5}(3.0 \mathrm{~g}$, $14.4 \mathrm{mmol}$ ). Stirring was continued for a few minutes at $0{ }^{\circ} \mathrm{C}$, followed by stirring at room temperature for about $2 \mathrm{~h}$. The solution was then filtered and concentrated to a pasty solid. The phosphorus oxychloride was removed by leaching with two 10$\mathrm{mL}$ portions of ether/hexane $(1 / 3 \mathrm{v} / \mathrm{v})$. The pale yellow solid was purified twice by precipitation from $\mathrm{CH}_{2} \mathrm{Cl}_{2}$ solution to hexane. The purified product was identified to be ACPC by the ${ }^{1} \mathrm{H}$ and ${ }^{13} \mathrm{C}$ NMR spectroscopy.

\section{Synthesis of ACP-MCM-41}

ACP-MCM-41 used as a radical initiator was synthesized by the method depicted in Figure 1. MCM-41 (2.0 g) was dehydrated under vacuum at $200^{\circ} \mathrm{C}$ for $2 \mathrm{~h}$ in a Schlenk tube before use. After cooling it to room temperature, MCM-41 was suspended in $\mathrm{CH}_{2} \mathrm{Cl}_{2}(20 \mathrm{~mL})$ under argon atmosphere. To a solution, ACPC (160 mg, $0.5 \mathrm{mmol})$ in $\mathrm{CH}_{2} \mathrm{Cl}_{2}(20 \mathrm{~mL})$ was added and stirred vigorously for $30 \mathrm{~min}$ in the presence of a small amount of triethylamine. Then, the mixture was stirred overnight at room temperature, and the reaction products were separated by a filtration, washed with an excess of $\mathrm{CH}_{2} \mathrm{Cl}_{2}$ to remove unreacted $\mathrm{ACPC}$, and dried under vacuum at room temperature. The reaction product was identified to be MCM41 by X-ray diffraction and IR spectroscopy. ${ }^{2}$ In the IR spectrum of the reaction product after extraction with $\mathrm{CH}_{2} \mathrm{Cl}_{2}$, new bands emerge at 2989, 2250, 1730, 1400-1480, and $1380 \mathrm{~cm}^{-1}$ assigned to be $\mathrm{C}-\mathrm{H},-\mathrm{CN}, \mathrm{C}=\mathrm{O}$, and $-\mathrm{CH}_{2}$ - and $-\mathrm{CH}_{3}$ groups, respectively, ${ }^{24}$ but the peak based on $\mathrm{C}=\mathrm{O}$ of $\mathrm{CO}-\mathrm{Cl}$ group $\left(1810 \mathrm{~cm}^{-1}\right)$ disappeared completely. This demonstrates that the covalently immobilized radical initiator on the inside wall of MCM-41, i.e., ACP-MCM-41 was synthesized. The amount of the initiator attached to the inside wall of MCM-41 was determined from TG/DTA measurement. From TG/DTA analysis, $0.44 \mathrm{mmol}$ ACPC per $1 \mathrm{~g}$ MCM-41 was attached covalently on the inside wall of the MCM- 41 .

\section{Polymerization Procedure}

ACP-MCM-41 was placed into a y-shaped glass tube with a rubber septum, and the glass tube was connected to a vacuum system. After the inside of the tube was kept high vacuum, MMA was charged in the tube by a syringe. The tube was subjected to several freeze-to-thaw cycles, and allowed to stand overnight at $5{ }^{\circ} \mathrm{C}$. Then, MMA-including ACP-MCM-41 was obtained by a removal of MMA which presents outside of the cavity of MCM-41, and then they put into a polymerization tube again. The amount of MMA charged in the cavity of MCM-41 determined by gravimetric method was $0.5 \mathrm{~g}$. The tube was degassed and sealed under high vacuum. After polymerization at a constant temperature for a given time, the contents of the tube were poured into a large amount of 
methanol. After dried under vacuum at room temperature, the product was suspended in $25 \mathrm{wt} \%$ aqueous $\mathrm{HF}(50 \mathrm{~mL})$ to isolate the polymer bonded to MCM-41 by destroying the framework of MCM-41. ${ }^{15}$ After the mixture was neutralized with aqueous $\mathrm{NaHCO}_{3}$, the resultant suspension was extracted with $\mathrm{CHCl}_{3}$ to isolate the polymer. The polymer yield was determined by gravimetric method.

In the polymerization of MMA with MAIB in the cavity of MCM-41, the charging of MMA and MAIB dissolved in the monomer into the cavity of MCM-41 was performed by a similar method described above. The tube was then subjected to several freeze-to-thaw cycles to degas, and sealed under high vacuum. After polymerization at a constant temperature for a given time, the contents of the tube were poured into a large amount of methanol. The silica compounds were removed by a filtration. The polymer yield was determined by gravimetric method.

\section{Post-polymerization of St}

After polymerization of MMA at $90^{\circ} \mathrm{C}$ for $2 \mathrm{~h}$ as described above, the residual unreacted MMA was evaporated at room temperature for $12 \mathrm{~h}$. St was then added in the tube by a syringe. The tube was degassed and sealed under high vacuum. After polymerization at $25^{\circ} \mathrm{C}$ for $24 \mathrm{~h}$, the contents of the tube were poured into a large amount of methanol. The product dried under vacuum at room temperature. It was then suspended in $25 \mathrm{wt} .-\%$ aqueous $\mathrm{HF}(50 \mathrm{~mL})$ to decompose the MCM-41 to isolate the copolymer formed. The mixture was stirred for $20 \mathrm{~min}$. and neutralized with aqueous $\mathrm{NaHCO}_{3}$. The resultant suspension was extracted with $\mathrm{CHCl}_{3}$, and the product was refluxed with cyclohexane for $24 \mathrm{~h}$ to remove poly $(\mathrm{St})$. Polymer yields were determined by gravimetric method.

\section{Polymer Characterization}

IR spectrum was recorded on a JASCO FT/IR-430 spectrometer. The amount of ACPC supported on the inside wall of MCM-41 was determined by thermogravimetric analysis (TGA). TGA measurement was carried out with a SEIKO TG/DTA 6200 in nitrogen stream at a heating rate of $10{ }^{\circ} \mathrm{Cmin}^{-1}$. The electron spin resonance (ESR) spectrum was taken using a Bruker ESP-300 spectrometer. Powder X-ray diffraction patterns were measured on a Shimadzu XD-610 diffractometer or a RIGAKU X-ray diffractometer RINTUltima with $\mathrm{CuK}_{\alpha}$ radiation. The number-average molecular weight $\left(M_{\mathrm{n}}\right)$, the weight-average molecular weight $\left(M_{\mathrm{w}}\right)$, and the dispersity index $\left(M_{\mathrm{w}} / M_{\mathrm{n}}\right)$ of the polymers were determined by gel permeation chromatography (GPC) using a Tosoh 8000 series system in tetrahydrofuran (THF) at flow rate of $1 \mathrm{~mL} /$ $\min$ at $38^{\circ} \mathrm{C}$. Standard polystyrenes were used for molecular weight calibration. The structure of polymer was analyzed by ${ }^{1} \mathrm{H}$ and ${ }^{13} \mathrm{C}$ NMR spectroscopy using a JEOL A-400 spectrometer in $\mathrm{CDCl}_{3}$ with TMS as an internal standard.

\section{RESULTS AND DISCUSSION}

Polymerization of MMA with ACP-MCM-41 in the Cavity Bulk polymerization of MMA with ACP-MCM-41 in the
Table I. Polymerization of MMA in bulk at $80^{\circ} \mathrm{C}$ with radical initiator ${ }^{\mathrm{a}}$

\begin{tabular}{lcccc}
\hline \multicolumn{1}{c}{ Initiator } & Time $(\mathrm{h})$ & Yield $(\%)$ & $M_{\mathrm{n}} \times 10^{-4}$ & $M_{\mathrm{w}} / M_{\mathrm{n}}$ \\
\hline ACP-MCM-41 & 1.0 & 15.8 & 27.9 & 2.86 \\
ACP-MCM-41 & 1.5 & 30.5 & 46.6 & 2.27 \\
ACP-MCM-41 $^{\text {MAIB }}$ & 3.0 & 49.4 & 76.0 & 1.72 \\
None $^{\mathrm{b}}$ & 1.0 & 87.7 & 0.57 & 3.20 \\
\hline
\end{tabular}

${ }^{\mathrm{a}}[\mathrm{ACP}-\mathrm{MCM}-41]=0.44 \mathrm{mmol} / g_{M C M-41},[\mathrm{MAIB}]=0.1 \mathrm{~mol} / \mathrm{L} .{ }^{\mathrm{b}}$ Polymerized in the cavity of MCM- 41 .

cavity of mesoporous silica at $80^{\circ} \mathrm{C}$ was carried out. The results are listed in Table $\mathrm{I}$, in which the results for the polymerization of MMA with dimethyl-2,2'-azobis(2-methyl propionate) (MAIB) are also indicated for comparison. No polymerization was induced without a radical initiator even in the presence of MCM-41. The rate of polymerization of MMA with ACP-MCM-41 immobilized covalently on the inside wall of MCM-41 was slower than that with MAIB which is not bonded to the wall of MCM-41. Although the reason is not clear, the low rate of the polymerization with ACP-MCM-41 may be explained by a cage effect of the initiator that is ascribed to the low diffusion of the radical fragment generated from ACP-MCM-41, leading to low initiator efficiency.

The molecular weight of polymer obtained with ACPMCM-41 was higher than any other polymerization systems examined, suggesting that the termination reaction was suppressed in the cavity of MCM-41. The formed product was extracted by $\mathrm{CHCl}_{3}$, and the amount of more than $83 \mathrm{wt}-\%$ was not extracted. The presence of extracted polymer suggests that a small amount of $\mathrm{COCl}$ group in ACPC may not be immobilized covalently on the inside wall of MCM-41. Graft density which determined from reported surface area of MCM- $41^{35}$ and a number of polymer chains obtained from the polymerization of MMA with ACP-MCM-41 was estimated to be $0.75 \times 10^{-3}$ chain $/ \mathrm{nm}^{2}$. This low value may be originated from restricted mobility of the initiating moiety bonded on the inside wall of the cavity.

Figure 2 shows TGA profiles for the product obtained from the polymerization of MMA in the presence of ACP-MCM-41 and poly(MMA) obtained from a conventional radical polymerization. Although poly(MMA) obtained from a conventional radical polymerization decomposed completely at $400{ }^{\circ} \mathrm{C}$, the polymer synthesized with ACP-MCM-41 gave the residue of $49.4 \%$ at $500^{\circ} \mathrm{C}$. Since poly(MMA) does not give any residues at $500{ }^{\circ} \mathrm{C}$, all residues obtained in this sample was suggested to be derived from the silica compound. The temperature of $5 \%$ weight loss was higher than that of the polymer obtained with MAIB.

\section{Kinetics on the Polymerization of MMA with ACP- MCM-41}

Termination reactions between the propagating radicals will be suppressed significantly by the restriction of the chain mobility in the cavity of MCM-41 in the polymerization of MMA with ACP-MCM-41, leading to the control of molecular weight of polymer. To elucidate this point, a kinetic study on 


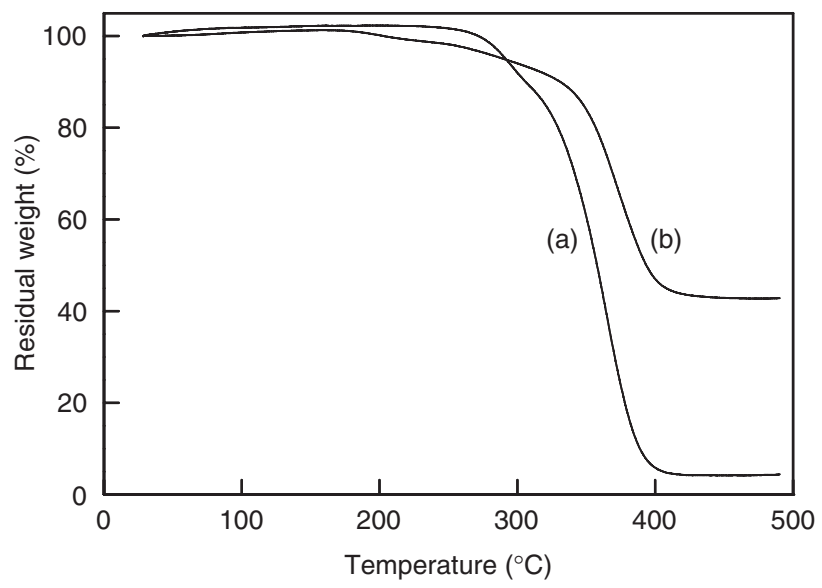

Figure 2. TGA curves of the product obtained from the polymerization of MMA with (a) ACPA and (b) ACP-MCM-41.

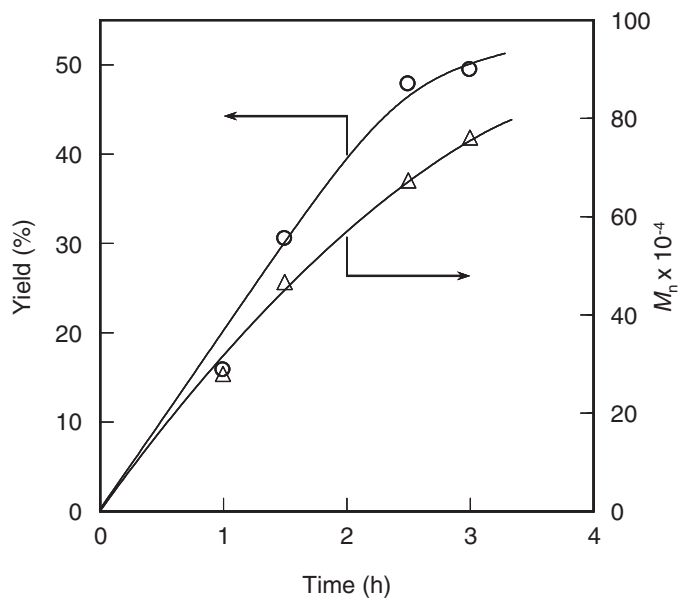

Figure 3. Polymerization of MMA in bulk with ACP-MCM- 41 at $80^{\circ} \mathrm{C}$; [Initiator $]=0.44 \mathrm{mmol} / \mathrm{g}_{\mathrm{MCM}-41}$.

the polymerization of MMA with ACP-MCM-41 was investigated. The results are shown in Figure 3. The polymer yields increased with reaction time, and the $M_{\mathrm{n}}$ of the polymer also increased as a function of reaction time. Since the polymerization of MMA takes place in the cavity of MCM-41 and the propagating chains is anchored on the inside wall of MCM-41, the termination reactions between two propagating radicals are prevented strongly by the restricted mobility of the chain.

The GPC elution curves of the polymer are shown in Figure 4, from which the whole elution curves shifted to the higher molecular weight side as a function of reaction time. Namely, chain transfer reactions and primary radical terminations may be ignored in the polymerization of MMA initiated with ACP-MCM-41 in the cavity of the mesoporous silica to yield a long lived propagating radical. Based on the results obtained from the kinetic study, it is clear that the molecular weight of the polymer can be controlled in the polymerization of MMA with ACP-MCM-41.

To elucidate further the mechanism in the polymerization of MMA with ACP-MCM-41, the first order plot for the

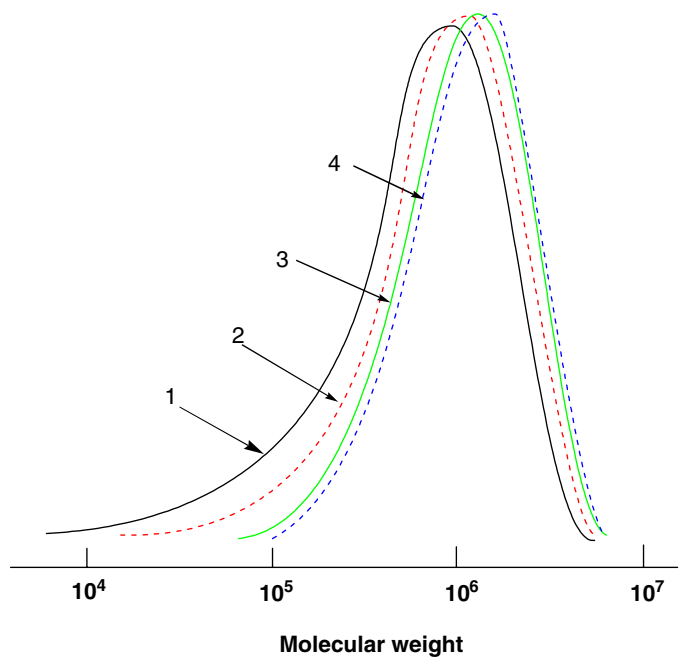

Figure 4. GPC elution curves for the polymerization of MMA with ACPMCM-41 for (1) $1.0 \mathrm{~h}$, (2) $1.5 \mathrm{~h}$, (3) $2.5 \mathrm{~h}$, and (4) $3.0 \mathrm{~h}$

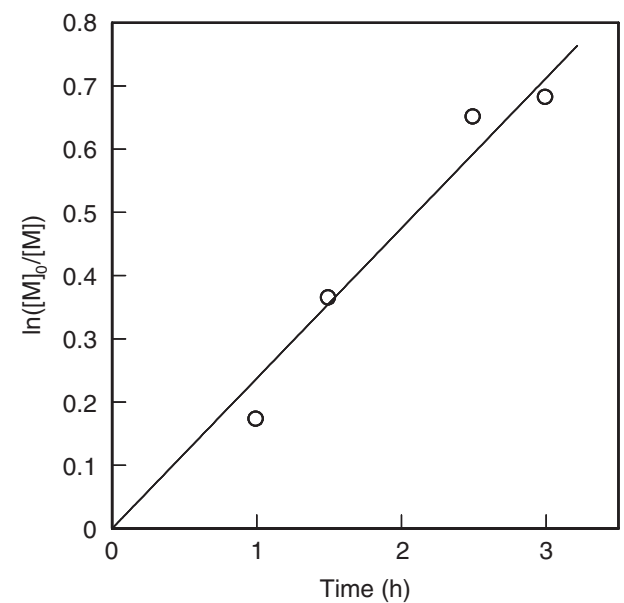

Figure 5. First order plot for the polymerization of MMA in bulk with ACP$\mathrm{MCM}-41$ at $80^{\circ} \mathrm{C}$; [Initiator] $=0.44 \mathrm{mmol} / \mathrm{g}_{\mathrm{MCM}-41}$.

polymerization was examined. $\ln [\mathrm{M}]_{0} /[\mathrm{M}]_{t}$ was plotted against reaction time $t\left([\mathrm{M}]_{0}\right.$ and $[\mathrm{M}]_{t}$ indicate the initial concentration of MMA and the concentration of MMA at a reaction time $t$, respectively), and the results are shown in Figure 5. The relationship between $\ln [\mathrm{M}]_{0} /[\mathrm{M}]_{t}$ and reaction time $t$ gave a straight line, and the line passed through the origin, suggesting that the concentration of the propagating radical kept constant during the polymerization.

To evaluate a molecular weight control of the polymer in the polymerization of MMA with ACP-MCM-41, the relationship between the $M_{\mathrm{n}}$ of the polymer and the polymer yield were plotted. The results are shown in Figure 6. The linear relation between polymer yield and molecular weight of polymer was observed even in the absence of special reagents such as transition metal chlorides in the atom transfer radical polymerization (ATRP), ${ }^{38}$ stable radicals such as nitroxides in the nitroxide mediated polymerization (NMP) ${ }^{39}$ and dithioesters in the radical addition-fragmentation-transfer (RAFT) polymer- 

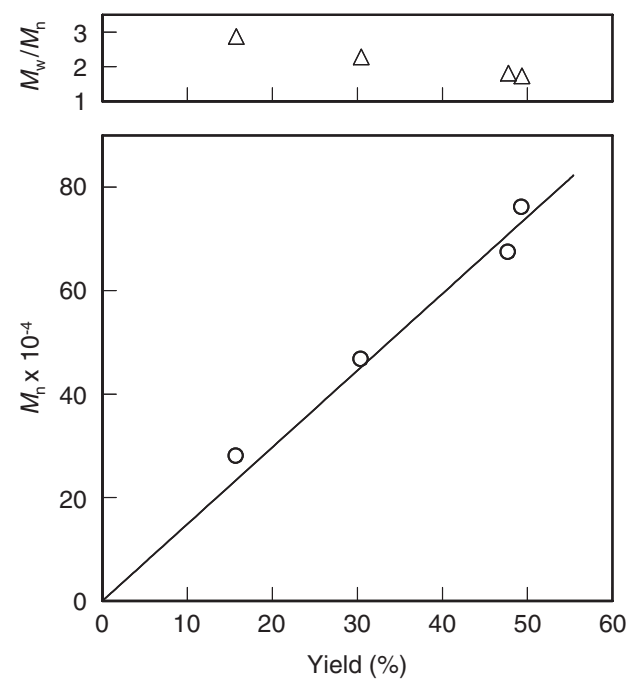

Figure 6. Relationship between polymer yield (\%) and $M_{\mathrm{n}}$ or $M_{\mathrm{w}} / M_{\mathrm{n}}$ for the polymerization of MMA in bulk with ACP-MCM- 41 at $80^{\circ} \mathrm{C}$; [Initiator $]=0.44 \mathrm{mmol} / \mathrm{g}-\mathrm{MCM}-41$.

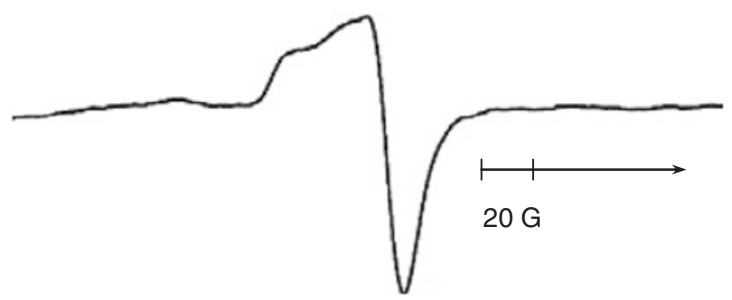

Figure 7. ESR spectrum of the propagating radical in the polymerization of MMA in bulk with ACP-MCM-41.

ization. ${ }^{40}$ The results suggest that the molecular weight control of the polymer can be possible, and the propagating radical in the cavity of MCM-41 lives for a prolonged time.

\section{Evaluation of Poly(MMA) Propagating Radicals}

The propagating radicals obtained from the polymerization of MMA with ACP-MCM-41 in the cavity of MCM-41 were estimated to be a long-lived radical. This was confirmed by an ESR spectroscopy. Figure 7 shows the ESR signal obtained at $25^{\circ} \mathrm{C}$ after the polymerization of MMA with ACP-MCM-41 at $90^{\circ} \mathrm{C}$ for $1.0 \mathrm{~h}$ was carried out. The ESR signals may be assigned as a propagating radical, since MCM-41 itself is known to be ESR-silent. ${ }^{41}$ The signal intensity as shown in Figure 7 is broadened without any hyperfine splitting. Similar results were reported in the previous paper. ${ }^{34}$ The change of the ESR signal intensity at $25^{\circ} \mathrm{C}$ as a function of the time was examined, and the results are shown in Figure 8. The signal intensity did not change significantly even after one week. This ESR profiles demonstrate that a long-lived propagating radical is produced in the polymerization of MMA with ACP-MCM-41 by suppression of termination reactions of the polymer-radicals due to the restricted mobility of polymer radicals in a spatially confined nano-cavity of MCM-41. Such suppression in our polymerization system may be stronger than that obtained from

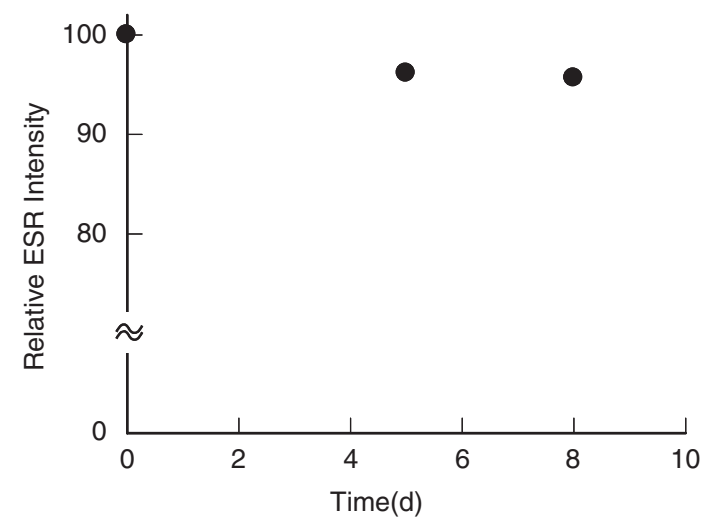

Figure 8. Change of intensity of the ESR signal stand at $25^{\circ} \mathrm{C}$ after the polymerization of MMA.

Table II. Post-polymerization of MMA with ACP-MCM- $41^{\mathrm{a}}$

\begin{tabular}{ccccc}
\hline \begin{tabular}{c}
$1^{\text {st }} \begin{array}{c}\text { Polymerization } \\
\text { Time }(\mathrm{h})^{\mathrm{b}}\end{array}$ \\
\hline 1
\end{tabular} & $\begin{array}{c}\text { Post-polymerization } \\
\text { Time }(\mathrm{h})^{\mathrm{c}}\end{array}$ & $\begin{array}{c}\text { Yield } \\
(\%)\end{array}$ & $M_{\mathrm{n}} \times 10^{-4}$ & $M_{\mathrm{w}} / M_{\mathrm{n}}$ \\
\hline 1 & - & 22.4 & 38.0 & 2.48 \\
0 & 24 & 35.6 & 52.7 & 1.83 \\
\hline
\end{tabular}

apolymerized in bulk, ACP-MCM- $41=0.5 \mathrm{~g}[0.4 \mathrm{mmol} / \mathrm{gMCM}-41]$ bolymerized at $90^{\circ} \mathrm{C}$. ${ }^{\mathrm{c}}$ Polymerized at $25^{\circ} \mathrm{C}$ after the first polymerization of MMA at $90^{\circ} \mathrm{C}$.

the polymerization with radical initiators non-bonded to the inside wall of MCM-41 described in a previous paper. ${ }^{34}$

\section{Post-Polymerization of MMA}

The post-polymerization at $25^{\circ} \mathrm{C}$ was investigated to confirm further the presence of a long-lived propagating radical generated from the polymerization of MMA with ACP-MCM-41, since it is difficult to generate a new initiation radical from the initiator at $25^{\circ} \mathrm{C}$. After the polymerization of MMA with ACP-MCM- 41 at $90^{\circ} \mathrm{C}$ for $1 \mathrm{~h}$, the reaction temperature was cooled down to $25^{\circ} \mathrm{C}$, and the post-polymerization was carried out continuously at $25^{\circ} \mathrm{C}$ for $24 \mathrm{~h}$. The results are shown in Table II. After the post-polymerization, the polymer yield and the $M_{\mathrm{n}}$ of the polymer increased in comparison to those of the original polymer. On the other hand, the polymerization of MMA with ACP-MCM-41 did not proceed at $25^{\circ} \mathrm{C}$. This indicates that the propagating radicals generated from the polymerization with ACP-MCM-41 are stable and long-lived.

Post-polymerization of $\mathrm{St}$ was also examined after the polymerization of MMA with ACP-MCM-41, and the results are listed in Table III. The $M_{\mathrm{n}}$ of the polymer and polymer yield were higher than those of parent poly(MMA). In the ${ }^{1} \mathrm{H}$ NMR spectrum of the post-polymerization product, the signal of aromatic protons due to St sequence appeared at 6.5$7.5 \mathrm{ppm}$ in addition to the signal based on PMMA segment. The GPC elution curve for the copolymer is shown in Figure 9. The elution curve shifted to higher molecular weight side after the post-polymerization. Thus, it is clear that long lived radical of poly(MMA) produced in the cavity of MCM- 41 . 
Table III. Polymerization of MMA and St with ACP-MCM- $41^{\mathrm{a}}$

\begin{tabular}{|c|c|c|c|c|}
\hline \multicolumn{2}{|c|}{ Time (h) } & \multirow[b]{2}{*}{ Yield (g) } & \multirow[b]{2}{*}{$M_{\mathrm{n}} \times 10^{-4}$} & \multirow[b]{2}{*}{$M_{\mathrm{w}} / M_{\mathrm{n}}$} \\
\hline $\begin{array}{c}\text { First } \\
\text { MMA }\left(90^{\circ} \mathrm{C}\right)\end{array}$ & $\begin{array}{c}\text { Second } \\
\text { St }\left(25^{\circ} \mathrm{C}\right)\end{array}$ & & & \\
\hline 2 & 0 & 0.11 & 39.0 & 3.33 \\
\hline 2 & 24 & $0.14^{b}$ & 43.6 & 3.64 \\
\hline
\end{tabular}

a $[$ Initiator $]=0.32 \mathrm{mmol} / \mathrm{g}_{\mathrm{MCM}-41}$ : determined by TGA of ACP-MCM-41. ${ }^{b}$ Measured after extraction with cyclohexane for $24 \mathrm{~h}$.

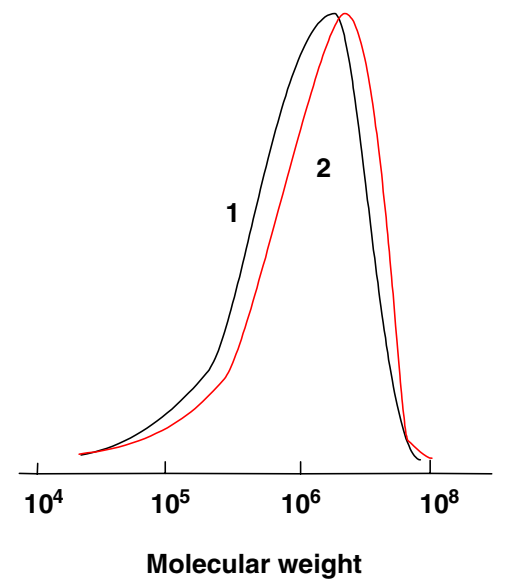

Figure 9. GPC elution curves of (1) parent poly(MMA) and (2) MMA-St block copolymer obtained with ACP-MCM-41.

\section{CONCLUSION}

The polymerization of MMA with ACP-MCM-41 immobilized covalently on the inside wall of MCM-41 gave a highmolecular weight polymer. The relationship between the $M_{\mathrm{n}}$ of the polymer and the polymer yield gave a straight line passed through the origin. The results demonstrate that the termination reactions of the propagating radicals were suppressed by the restricted mobility of polymer radicals in the nano-cavities of MCM-41 to give a long-loved polymer radical, leading to the molecular weight control of the polymer. The presence of the long-live propagating radical was supported by the ESR measurement and the post-polymerization of MMA and St.

Received: December 26, 2008

Accepted: May 8, 2009

Published: June 24, 2009

\section{REFERENCES}

1. A. P. Wight and M. E. Davis, Chem. Rev., 102, 3589 (2002).

2. a) C. T. Kresge, M. E. Leonowicz, W. J. Roth, J. C. Vartuli, and J. S. Beck, Nature, 359, 710 (1992).

b) J. S. Beck, J. C. Vartuli, W. J. Roth, M. E. Leonowicz, C. T. Kresge, K. D. Schmitt, C. T.-W. Chu, D. H. Olson, E. W. Sheppard, S. B. McCullen, J. B. Higgins, and J. L. Schlenker, J. Am. Chem. Soc., 114, 10834 (1992).

3. T. Yanagisawa, T. Shimizu, K. Kuroda, and D. Kato, Bull. Chem. Soc. Jpn., 63, 988 (1990).
4. T. Maschmeyer, F. Rey, G. Ssnker, and J. M. Thomas, Nature, 378, 159 (1995).

5. X. Feng, G. E. Fryxell, L.-Q. Wang, A. Y. Kim, J. Liu, and K. M. Kemner, Science, 276, 923 (1997).

6. a) N. Liu, Z. Chen, D. R. Dunphy, Y. B. Jiang, R. A. Assink, and C. J. Brinker, Angew. Chem., Int. Ed., 42, 1731 (2003). b) N. Liu, D. R. Dunphy, P. Atanassov, S. D. Bunge, Z. Chen, G. P. Lopez, T. J. Boyle, and C. J. Brinker, Nano Lett., 4, 551 (2004).

7. N. K. Mal, M. Fujiwara, and Y. Tanaka, Nature, 421, 350 (2003).

8. a) K. Inumaru, J. Kiyoto, and S. Yamanaka, Chem. Commun., 903 (2000).

b) K. Inumaru, Y. Inoue, S. Kakii, T. Nakano, and S. Yamanaka, Chem. Lett., 32, 1110 (2003).

9. K. Kageyama, J. Tamazawa, and T. Aida, Science, 285, 2113 (1999).

10. Y. S. Ko, T. K. Han, J. W. Park, and S. I. Woo, Macromol. Rapid Commun., 17, 749 (1996).

11. a) J. Tudor and D. O'Hare, Chem. Commun., 603 (1997).

b) S. O'Brien, J. Tudor, T. Maschmeyer, and D. O'Hare, Chem. Commun., 1905 (1997).

c) C. J. Miller and D. O'Hare, Chem. Commun., 1710 (2004).

12. L. K. Van Looveren, D. F. Geysen, K. A. Vercruysse, B. H. Wouters, P. Grobet, and P. A. Jacobs, Angew. Chem., Int. Ed., 37, 517 (1998).

13. M. Kwanten, B. A. M. Carrière, P. J. Grobet, and P. A. Jacobs, Chem. Commun., 1508 (2003)

14. a) R. R. Rao, B. M. Weckhuysen, and R. A. Schoonheydt, Chem. Commun., 445 (1999).

b) B. M. Weckhuysen, R. R. Rao, J. Pelgrims, R. A. Schoonheydt, P. Bodart, G. Debras, O. Collart, P. V. D. Voort, and E. F. Vansant, Chem. Eur. J., 6, 2960 (2000).

15. a) M. Pillinger, I. S. Gonçalves, P. Ferreira, J. Rocha, M. Schäfer, D. Schön, O. Nuyken, and F. E. Kühn, Macromol. Rapid Commun., 22, 1302 (2001).

b) M. Pillinger, I. S. Gonçalves, A. D. Lopes, P. Ferreira, J. Rocha, G. Zhang, M. Schäfer, O. Nuyken, and F. E. Kühn, Phys. Chem. Chem. Phys., 4, 696 (2002).

16. H. Balcar, J. Sedláček, J. Čejka, and J. Vohlídal, Macromol. Rapid Commun., 23, 32 (2002).

17. Z. Ye, H. Alayouri, S. Zhu, and Y. S. Lin, Polymer, 44, 969 (2003).

18. D. J. Cardin, S. P. Constantine, A. Gilbert, A. K. Lay, M. Alvaro, M. S. Galletero, H. Garcia, and F. Marquez, J. Am. Chem. Soc., 123, 3141 (2001).

19. K. Moller, T. Bein, and R. X. Fischer, Chem. Mater., 10, 1841 (1998).

20. P. L. Llewellyn, U. Ciesla, H. Becher, R. Stadler, F. Schüth, and K. K. Unger, Stud. Surf. Sci. Catal., 84, 2013 (1994).

21. M. Choi, F. Kleitz, D. Liu, H. Y. Lee, W. Ahn, and R. Ryoo, J. Am. Chem. Soc., 127, 1924 (2005).

22. W. C. Molenkamp, M. Watanabe, H. Miyata, and S. H. Tolbert, J. Am. Chem. Soc., 126, 4476 (2004).

23. E. J. Acosta, C. S. Carr, E. E. Simanek, and D. F. Shantz, Adv. Mater., 16, 985 (2004).

24. O. Prucker and J. Rühe, Macromolecules, 31, 592 (1998).

25. B. Zhao and W. J. Brittain, Prog. Polym. Sci., 25, 677 (2000)

26. M. Ejaz, Y. Tsujii, and T. Fukuda, Polymer, 42, 6811 (2001).

27. G. Carrot, S. Diamanti, M. Manuszak, B. Charleux, and J.-P. Vairon, J. Polym. Sci., Part A: Polym. Chem., 39, 4294 (2001).

28. T. von Werne and T. E. Patten, J. Am. Chem. Soc., 123, 7497 (2001).

29. K. Ohno, T. Morinaga, K. Koh, Y. Tsujii, and T. Fukuda, Macromolecules, 38, 2137 (2005).

30. M. Save, G. Granvorka, J. Bernard, B. Charleux, C. Boissière, D. Grosso, and C. Sanchez, Macromol. Rapid Commun., 27, 393 (2006).

31. S. Blomberg, S. Ostberg, E. Harth, A. W. Bosman, B. Van Horn, and C. J. Hawker, J. Polym. Sci., Part A: Polym. Chem., 40, 1309 (2002).

32. Q. Fu, G. V. R. Rao, L. K. Ista, Y. Wu, B. P. Andrzejewski, L. A Sklar, T. L. Ward, and G. P. López, Adv. Mater., 15, 1262 (2003).

33. M. Kruk, B. Dufour, E. B. Celer, T. Kowalewski, M. Jaroniec, and K. Matyjaszewski, J. Phys. Chem. B, 109, 9216 (2005).

34. S. M. Ng, S. Ogino, and T. Aida, Macromol. Rapid. Commun., 18 
991 (1997).

35. T. R. Pauly, V. Petkov, Y. Liu, S. J. L. Billinge, and T. J. Pinnavaia, J. Am. Chem. Soc., 124, 97 (2002).

36. S. Spange, A. Gräser, H. Müller, Y. Zimmermann, P. Rehak, C. Jäger, H. Fuess, and C. Baehtz, Chem. Mater., 13, 3698 (2001).

37. D. A. Smith, Makromol. Chem., 103, 301 (1967).

38. a) M. Kato, M. Kamigaito, M. Sawamoto, and T. Higashimura, Macromolecules, 28, 1721 (1995).

b) J.-S. Wang and K. Matyjaszewski, J. Am. Chem. Soc., 117, 5614
(1995).

39. M. K. Georges, R. P. N. Veregin, P. M. Kazmaier, and G. K. Hamer, Macromolecules, 26, 2987 (1993).

40. J. Chiefari, Y. K. Chong, F. Ercole, J. Krstina, J. Jeffery, T. P. T. Le, R. T. A. Mayadunne, G. F. Meijs, C. L. Moad, G. Moad, E. Rizzardo, and S. H. Thang, Macromolecules, 31, 5559 (1998).

41. M. Kamachi, M. Kohno, D. J. Liaw, and S. Katsuki, Polym. J., 10, 69 (1978). 